\title{
A Mobile-Based Screening System for Data Analyses of Early Dementia Traits Detection
}

\author{
Fadi Thabtah \\ Manukau Institute of \\ Technology \\ Auckland, New Zealand \\ Fadi.fayez@manukau.ac.nz \\ Ella Mampusta \\ Manukau Institute of \\ Technology \\ Auckland, New Zealand \\ David Peebles \\ University of \\ Huddersfield \\ Huddersfield, UK \\ Raymund Herradura \\ Manukau Institute of \\ Technology \\ Auckland, New Zealand \\ jithin varghese \\ Manukau Institute of \\ Technology \\ Auckland, New Zealand
}

\begin{abstract}
Existing early detection methods that deal with the pre-diagnosis of dementia have been criticised as not being comprehensive as they do not measure certain cognitive functioning domains besides being inaccessible. A more realistic approach is to develop a comprehensive outcome that includes cognitive functioning of dementia, as this will offer a robust and unbiased outcome for an individual. In this research, a mobile screening application for dementia traits called DementiaTest is proposed, which adopts the gold standard assessment criteria of Diagnostic and Statistical Manual of Mental Disorders (DSM-V). DementiaTest is implemented and tested on the Android and IOS stores. More importantly, it collects data from cases and controls using an easy, interactive, and accessible platform. It provides patients and their family with quick pre-diagnostic reports using certain cognitive functioning indicators; these can be utilized by general practitioners (GPs) for referrals for further assessment in cases of positive outcomes. The data gathered using the new application can be analysed using Artificial Intelligence methods to evaluate the performance of the screening to pinpoint early signs of the dementia.
\end{abstract}

\section{Keywords}

Accessibility, Data Analyses, Dementia, Cognitive impairment, Health Informatics, Mobile application, Mobile Health

\section{Introduction}

Recent technology developments have improved humans' quality of life and increased the average lifespan. Many countries are facing an aging society, and this requires specialised health services. Dementia presents one of the most progressive groups of symptoms in old people, and the number of diagnosed patients is increasing. This poses serious challenges for the healthcare systems as well as for the patients and their families. Dementia is the result of neurodegeneration represented in a group of symptoms that damages human brain cells; it is associated with memory loss, and behavioural, cognitive, and communication difficulties (Panegyres, Berry, \& Burchell 2016). 
Dementia is often progressive, such as in Alzheimer's disease, as traits exhibited by the patient gradually worsen, influencing the patient's ability to perform daily tasks. According to (WHO, 2017) there are 50 million people worldwide living with dementia and the number is increasing every year by 10 million.

Dementia becomes a common problem for people over 65 years old, and sometimes it afflicts young people as well (Deloitte, 2017). Alzheimer's and vascular dementia are the most common dementia diseases (Cunningham et al., 2015; Gorelick et al., 2011). Health conditions like heart problems, high cholesterol, high blood pressure, and possibly diabetes can increase the probability of developing dementia (Fan et al., 2017). Therefore, it is imperative to identify dementia symptoms as early as possible to provide appropriate healthcare support to the patients and their caregivers. Dementia has a huge economic and social impact in terms of medical support and social care; the estimated cost of dementia within the global scale in 2015 was USD 818 billion (WHO, 2017).

Dementia, if not detected, becomes more prominent in patients aged 65 years or older; not exposing these people to early intervention and treatment can have a negative impact on their lives. Detecting dementia traits early is advantageous to the patients, caregivers, and healthcare service providers. There is no specific test for detecting dementia, yet scholars in the areas of neurology or gero-psychology utilise cognitive tests such as MCl (Harrison, et al. 2016; Langa \& Levine, 2014) that pinpoint pre-dementia traits. $\mathrm{MCl}$ measures the decline in reasoning which is greater than the average level expected for a person's education and age (Panegyres et al., 2016). The $\mathrm{MCl}$ test evaluates criteria related to individuals' interaction with daily activities and cognitive performance; these criteria are adopted from diagnostic criteria for Alzheimer's disease (Panegyres et al., 2016). Overall, the diagnostic process of dementia as a major neurocognitive disorder is based on revised criteria defined in the Diagnostic and Statistical Manual of Mental Disorders (DSM-V) (APA, 2013). These criteria concentrate mainly on both memory and cognitive impairments.

There are a few dementia screening methods that have been developed by researchers in neurology and gero-psychology domains that primarily focus on the decline of cognitive ability, such as the mini mental state examination (MMSE) and the Montreal cognitive assessment (MoCA) (Tanrivedi, 2018; Jefferies et al., 2013a; Waite, 2010). MMSE evaluates any reasoning impairment on a scale from 0 to 30 in a 15-minute screening test in which a score of 26 indicates poor reasoning ability. Studies have shown that this dementia screening test achieved specificity of $65 \%-90 \%$ and sensitivity of $45 \%-60 \%$ (Tanrivedi, 2018). On the other hand, MoCA achieved better specificity and sensitivity than MMSE at 50\%-76\% and $>80 \%$ respectively according to research studies (Jefferies et al., 2013; Tanrivedi, 2018). The available screening methods only focus on the cognitive area and very few screening tests deal with functioning activities, i.e. IQCODE (Jorm et al., 1991). More importantly, there are very limited mobile screening applications to enable accessing cognitive functioning of dementia in a single platform, which indeed can be advantageous. Currently, very few dementia screening applications are available such as SoCA, MMSE, and Mental Health (Tanrivedi, 2018; Mind Diagnostics, 2018). However, these applications deal with cognitive questions only.

This paper proposes a new interactive and accessible screening method for dementia called DementiaTest which covers cognitive functioning. Patients in the early stage of dementia, caregivers, and diagnosticians are now able to measure dementia traits as early as possible using the DementiaTest mobile application. This new application integrates two conventional screening methods, namely 6-CIT and SCIDS, in an automated and secured way to improve early dementia screening. The key added values of DementiaTest are: its reliability, as it will be fulfilled under the gold standard of evaluating neurology health disorders, and its accessibility, as it is available to individuals or primary healthcare providers that have access to a mobile device and the internet. Existing conventional screening methods require an individual who wants to undergo dementia screening to visit a primary healthcare clinic or hospital to participate; the resulting scores are then interpreted manually by a medical practitioner. Other values offered by this mobile application are 
efficiency and effectiveness, achieved by reducing delays and saving time in updating, retrieving, and communicating results. This research would be beneficial to screening test participants, their caregivers, medical staff, GPs, and clinicians among others.

This research reviews existing mobile applications for the early detection of dementia that are available in the Apple and Google Play stores, as well as the typical pre-diagnosis methods in Section 2. Section 3 discusses the development of DementiaTest and its major components, functionalities, and characteristics. Lastly, we conclude in Section 4.

\section{Literature Review}

The Global Observatory of electronic health (GOeh) categorises medical and public health practices that are supported by mobile devices, such as patient-monitoring devices, (Personal Digital Assistants (PDAs)), as mHealth or mobile health (WHO, 2011). Essentially, mHealth utilises the core capability of a mobile device such as short messaging system (SMS), Bluetooth technology, general packet radio service (GPRS), $3^{\text {rd }}$ and $4^{\text {th }}$ mobile telecommunication systems ( $3 G$ and $4 G$ ), and the global positioning system (GPS). This section describes and critically analyses the different mHealth applications for early dementia screening. In addition, common dementia screening tests, such as 6CIT and SCIDS, that embody the developed app are discussed.

\subsection{Existing Dementia Screening Mobile Application integrating 6-CIT}

Confusion: Delirium \& Dementia: A Bedside Guide

A mHealth application was developed for specific geriatric disease to identify cognitive impairment employing assessment methods such as 6-CIT, the CAM (Confusion Assessment Method), the Abbreviated Mental Test (AMT), the Montreal Cognitive Assessment (MoCA) which is available in the app store (Berauk et al., 2017). This app basically offers information on the varieties of dementia and delirium. This test covers the cognitive domains of memory, calculation, and orientation including $\mathrm{MCl}$. According to (Berauk et al., 2017), the app is delivered through a mix of e-learning and clinical bedside which incorporates a battery of tests that can be selected from the menu preference screen. The app is targeted at doctors to take a structured approach in their assessments towards a confused patient, and for discriminating against delirium and dementia. The app features include: a size of less than 150 megabytes, diagnostic and assessment tools, a drugs-interaction checker, and information on disease management (treatment/ prevention).

\section{ConsultGeri: Dementia}

This app is designed for the consumption of healthcare professionals or caregivers as it offers a methodological approach to diagnosis and a management guide for patients suffering $\mathrm{MCl}$ and Alzheimer's disease. It was developed at New York University under the expertise of the Hartford Institute of Geriatric Nursing (HIGN). This mHealth app is available via the AppStore and its size is less than 150 megabytes; it has diagnostic and assessment tools but lacks some useful features like a drug-interaction checker, dosage recommendations and indications, and disease information. This app is recommended for the management, diagnosis, and assessment of the elderly population (Berauk, 2017). The cognitive parameters gauged are orientation, memory, attention, thinking, language, praxis, and executive function (NYU, 2015).

Although the 6-CIT method is integrated in the Delirium and Dementia mHealth app, it is not selfadministered, hence requires the presence of a healthcare practitioner to implement the screening process. 
This is a mHealth app that operates on android and is targeted to screen participants aged 72-82 years old; it was developed as neuropsychological test software that comprises 33 questions in 14 types of tests to examine 8 different cognitive domains. The app does not specifically employ the Short Concord Informant Dementia Scale (SCIDS) questionnaire but covers the functional tasks of memory and orientation that is incorporated into the SCIDS method. Although MCS is unpublished in the play store, it is well researched and studied with statistical findings and comparisons to MoCA (Zorluoglua, 2014). But there are limitations observed from this study: (i) There are less than 30 participants, thus requiring a larger base of participants to validate the test. (ii) A fixed set of questions are asked whenever the application is used, thus making it difficult to track a person's cognitive progress. (iii) The test language is in Turkish, but the software is adaptable to any other language. Nonetheless, MCS can differentiate between healthy cognitive functioning and cognitive impairment.

\section{Montreal Cognitive Assessment (MoCA)}

MoCA is a commonly used assessment test in literature and categorised as a paper-and-pencil domain that evaluates memory, the visuospatial process, attention, orientation, naming, abstraction, recall and language functions (Zorluoglua, 2014). As discussed by (Nasreddine et al., 2005), this test was developed to evaluate the early stages of cognitive impairment and contains 10 questions and can be completed in approximately 10 minutes. The test is translated into 36 different languages including dialects and is freely available for use on the MoCA official website. The sensitivity, or ability to distinguish participants with dementia, is at $100 \%$, and for those without dementia it is at $87 \%$ respectively; this establishes its ground as a reliable form of screening $\mathrm{MCl}$. When a participant reaches 21 points it is considered in a position of normal cognitive capacity.

\subsection{Cognitive Questionnaire Screening Mobile Applications}

This section presents the available screening tests for dementia developed for mobile devices. All the applications discussed comprise a screening test for distinguishing dementia. Non-screening applications such as educational, dementia handling, and awareness applications are not covered in this section.

\section{SOCA Dementia Early Detection}

Sensitive Online Cognitive Assessment (SOCA) is similar to MoCA which is a widely used screening method for identifying cognitive impairment. The target of this application is to exclude dementia as an outcome of the test. The test includes 13 questions divided into 8 distinct categories that evaluate the cognitive skills of the brain. SOCA is a cognitive screening test that covers logic, coordination, naming, memory, attention, language, abstraction, and orientation. The outcome of the test is derived based on a points-system that signifies the correct answers. The scoring ranges from 0 to 31; scores reaching 26 and above are rated 'without dementia'. Whilst, marks obtained between 22 and 25 denote signs of early dementia; any score achieved below 22 signifies

participants with dementia. However, this app covers cognitive impairment only (Wascher, 2018).

MMSE

This is a commonly used brief cognitive assessment tool for a variety of cognitive disorders which comprises a short battery of tests that covers 11 domains with a total of 30 points. This mHealth application was developed to undertake the Mini Mental State Examination (MMSE) test on mobile platforms. The MMSE test is for screening cognitive skills which is a measure of cognitive impairment

(Tanrivedi, 2018) and is more widely used than other screening methods. The maximum score is 30 points; a score of $24-30$ is considered normal, 20 - 24 suggests mild dementia, 13 - 20 is considered as moderate dementia, and a score of less than 12 is considered as severe dementia. The time required to administer MMSE is between 7-10 minutes. It has 11 questions which measure 5 areas of cognitive function including language, recall, attention, calculation, orientation, and registration. 


\section{Dementia \& Alzheimer's Memory Diagnosis Test}

This mHealth application is comprised of 10 questions which cover the cognitive domains of memory, language, and visual-spatial skills. This application is for self-assessment of mental health and employs the MMSE test as a screening method. MMSE has a sensitivity of $79 \%$ and specificity of $95 \%$, thus makes it a good selection to be integrated with this app as I its reliable in distinguishing participants exhibiting cognitive impairment related to dementia. This app comprises 10 questions that evaluate cognitive skills and it utilises interactive methods such as audio input and output. The approximate time to accomplish the test is $7-10$ minutes; the questions used for screening are unchanging and a similar set is used every time the application is launched making it difficult to track the progress of a participant.

\section{Mental Health Test}

This mHealth app provides a battery of tests for over 25 different mental health issues that includes tests for the following: depression, anxiety, adult ADHD, PTSD, alcohol/substance abuse and addiction, eating disorders, gambling addiction, mania, narcissism, sex addiction, video game addiction, internet addiction, toxic workplace, panic disorder, obsessive compulsive disorder, male sexual dysfunction, female aggression, male aggression, female sexual dysfunction, social anxiety disorder, hoarding disorder, psychosis, personality disorder, dissociative identity disorder, and schizophrenia (Mind Diagnostics, 2018). All the tests use the Patient Health Questionnaire (PHQ-9) method for screening. Each test has nine questions and takes approximately five minutes. This application can track the cognitive process over time. The outcomes can be provided to a friend, family, or therapist; it can also help to locate a therapist in your area (this feature is only available in the US region).

\section{Cognitive Questionnaire Test}

This mHealth app evaluates the cognitive capacity of the brain and involves three sections for screening: the arithmetic section, number sequencing, and reaction time (Chaturvedi, 2018). The arithmetic section includes essential maths-related questions such as addition and subtraction. The other questions are multiple choice with four different options that includes a one-minute timer. The scoring method is achieved by contrasting the number of correctly answered questions against the total number of questions attempted. In number sequencing, a series of five-digit numbers is displayed for 10 seconds and then the participant must provide the number as an input for the answer. After every correct attempt the number sequence increases by one place value, making it more difficult to remember. Lastly, the reaction time utilises a stopwatch timer to validate the time difference required to make an action. A random set of questions is provided every time the application is launched which makes the cognitive process of an individual easy to track.

\section{eSLUMS}

This mHealth app, electronic Saint Louis University Mental Status (eSLUMS) exam, was developed by Dr Theodore K. Malmstorm and Dr John Morley from Saint Louis University School of Medicine to detect early dementia and $\mathrm{MCl}$ (Chewy Logic, 2018). The application design is interactive and userfriendly and takes approximately 7-10 minutes to complete. Upon accomplishing the test, there is a feature that provides a report in portable document format. Other features include: ease of test administration, automatic scoring, scoring instructions, test administration with audio prompts, and result availability on iPhone. A professional version is available, for a fee, that provides a comprehensive report, the patient's history, and clinician administered tests.

\subsection{Discussion}

Tables 1 and 2 show existing dementia screening applications and other applications that rely on the 6-CIT dementia screening method, along with different criteria. Based on Table 1, the most popular 
app is the Mental Health Test with over 50,000 downloads. The lowest rating app was obtained by Dementia and Alzheimer's memory at 3.8 stars with minimal reviewers. SoCA and MMSE were interactive apps as they utilise both audio and images to conduct the dementia test. All of the applications are readily available in the English language thus reaching a majority of mobile phone users. Nevertheless, one of the major shortcomings associated with these mHealth apps in Tables 1 and 2 is that they all deal with just cognitive functions and do not cover other impairments related to dementia, particularly cognitive deficits, which are what impedes the independence of an individual pertaining to everyday living. According to the DSM-V (APA, 2013) which defines cognitive deficits as the incapacity of an individual to participate in functional activities such as management of medications, handling of finances, and social functions, this definition covers the areas of neurocognitive domains such as complex attention and executive functions. Given the assessment guidelines from DSM-V, most of the apps in Table 1 lack the functional screening capability which will be fulfilled by our proposed DementiaTest app.

The last three apps in Table 2 are designed for healthcare professionals, whereas the proposed DementiaTest app integrates 6-CIT for administration by the caregiver or family member on behalf of the participants. The proposed DementiaTest app will also cover both cognitive and functional screening methods providing a comprehensive result and thus offering a reliable, valid, and consistent outcome. It will not be biased towards the cognitive capacity of an individual, rather there will be an element of a third-party represented by a caregiver that is tasked to provide valuable information about the historical memory performance of the participant. 
Table 1. Existing Dementia Screening Apps and their Features.

\begin{tabular}{|c|c|c|c|c|c|c|c|c|c|c|c|c|}
\hline mHealth & Developer & Target & Rating & Reviews & $\begin{array}{l}\text { Apple } \\
\text { iTunes }\end{array}$ & $\begin{array}{l}\text { Google } \\
\text { Store }\end{array}$ & $\begin{array}{l}\text { Audio } \\
\text { Use }\end{array}$ & $\begin{array}{l}\text { Images } \\
\text { Use }\end{array}$ & Screening & $\begin{array}{c}\text { No. of } \\
\text { questions }\end{array}$ & Downloads & Reference \\
\hline eSLUMS & $\begin{array}{c}\text { Chewy } \\
\text { Logic LLC }\end{array}$ & N/A & N/A & N/A & $\sqrt{ }$ & $x$ & $\sqrt{ }$ & $x$ & $\sqrt{ }$ & 24 & N/A & (Chewy Logic LLC 2018) \\
\hline $\begin{array}{l}\text { Dementia Test- Risk } \\
\text { Calculator of Dementia }\end{array}$ & $\begin{array}{l}\text { Pears } \\
\text { Health } \\
\text { Cyber }\end{array}$ & $\mathrm{N} / \mathrm{A}$ & $\mathrm{N} / \mathrm{A}$ & N/A & $\sqrt{ }$ & $\mathrm{x}$ & $\mathrm{x}$ & $\mathrm{x}$ & $\sqrt{ }$ & 10 & N/A & (Cyber, 2018) \\
\hline $\begin{array}{l}\text { Dementia and } \\
\text { Alzheimer's Memory } \\
\text { Diagnosis Test: MMSE }\end{array}$ & $\begin{array}{c}\text { Dementia } \\
\text { Analysis }\end{array}$ & N/A & 3.8 & 8 & $x$ & $\overline{\sqrt{ }}$ & $\sqrt{ }$ & $\mathrm{x}$ & $\sqrt{ }$ & 10 & $1000+$ & (Analysis, 2018) \\
\hline SOCA & $\begin{array}{l}\text { Thomas } \\
\text { Wascher }\end{array}$ & $\begin{array}{l}50 \text { and } \\
\text { above }\end{array}$ & 4 & 4 & $x$ & $\sqrt{ }$ & $\sqrt{ }$ & $\sqrt{ }$ & $\sqrt{ }$ & 13 & $50+$ & (Wascher, 2018) \\
\hline $\begin{array}{l}\text { Cognitive } \\
\text { Questionnaire Test }\end{array}$ & $\begin{array}{c}\text { Kunal } \\
\text { Chaturved } \\
\mathrm{i}\end{array}$ & $\begin{array}{l}18 \text { and } \\
\text { above }\end{array}$ & - & 2 & $x$ & $\sqrt{ }$ & $x$ & $x$ & $x$ & na & $100+$ & (Chaturvedi 2018) \\
\hline Mental Health Test & $\begin{array}{c}\text { Mind } \\
\text { Diagnostic } \\
\text { Inc }\end{array}$ & $\mathrm{Na}$ & 3.9 & 79 & $\sqrt{ }$ & $\sqrt{ }$ & $x$ & $\sqrt{ }$ & $\sqrt{ }$ & 9 & $50,000+$ & Mind Diagnostics, 2018) \\
\hline MMSE & $\begin{array}{c}\text { Yasin } \\
\text { Tanriverdi }\end{array}$ & $\begin{array}{l}18 \text { and } \\
\text { above }\end{array}$ & 3.9 & 44 & $x$ & $\sqrt{ }$ & $\sqrt{ }$ & $\sqrt{ }$ & $\sqrt{ }$ & 13 & $1000+$ & (Tanriverdi, 2018) \\
\hline
\end{tabular}


Table 2: Existing Mobile Apps that Utilise 6-CIT Dementia Screening Methods

\begin{tabular}{|c|c|c|c|c|c|c|c|c|c|c|c|c|}
\hline mHealth & Developer & $\begin{array}{c}\text { Targe } \\
\mathrm{t}\end{array}$ & Rating & Reviews & $\begin{array}{c}\text { Apple } \\
\text { iTune } \\
\mathrm{s}\end{array}$ & $\begin{array}{l}\text { Goog } \\
\text { le } \\
\text { Store }\end{array}$ & $\begin{array}{l}\text { Audio } \\
\text { Use }\end{array}$ & $\begin{array}{c}\text { Imag } \\
\text { es } \\
\text { Use }\end{array}$ & $\begin{array}{c}\text { Scree } \\
\text { ning }\end{array}$ & $\begin{array}{l}\text { No. } \\
\text { of } \\
\text { ques } \\
\text { tions }\end{array}$ & $\begin{array}{l}\text { Down } \\
\text { loads }\end{array}$ & Reference \\
\hline $\begin{array}{l}\text { MCS (Mobile } \\
\text { Cognitive Screening) }\end{array}$ & $\begin{array}{l}\text { Istanbul } \\
\text { Technical } \\
\text { University }\end{array}$ & 73-89 & $\mathrm{N} / \mathrm{A}$ & N/A & N/A & N/A & N/A & $\mathrm{N} / \mathrm{A}$ & $\sqrt{ }$ & 33 & N/A & (Zorluoglua, 2014) \\
\hline
\end{tabular}




\section{Proposed Dementia Screening Mobile Application (DementiaTest)}

This mobile application is developed in the Android official Integrated Development Environment (IDE) platform as well as IOS. There are five major components involved with the DementiaTest mobile application workflow: (i) An interface that will act as the portal for data acquisition; (ii) The user, who is the primary source of data which is either self-administered or with the aid of a caregive; r (iii) Screening methods, the core of the application in providing assessments whether or not a participant has a high potential of attaining dementia; (iv) An API (Application Programming Interface) that acts as a gateway to interact with the cloud database in terms of data storage and retrieval in a secured manner; (v) The database, Firebase, (Google Developers, 2018), is the cloud storage where the data is stored, retrieved, and manipulated. In this section, we explain these components in detail and pinpoint the major functionalities and screening of the DementiaTest app.

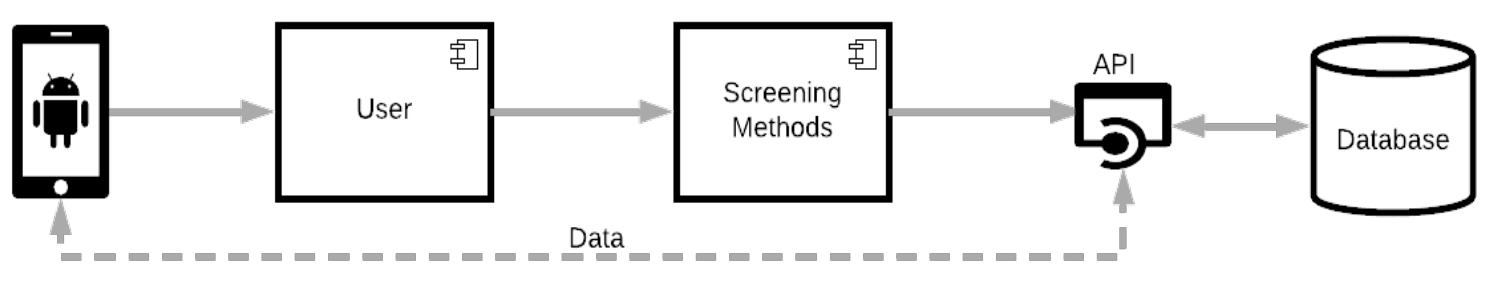

Figure 1: DementiaTest Application Component Diagram.

\subsection{Screening Method}

There are two screening methods synergised as an integral part of the DementiaTest mobile app: the 6-CIT (6-Cognitive Impairment Test), and SCIDS (Short Concord Informant Dementia Scale) (Jefferies et al., 2013; Waite, 2010). Specifically, the DementiaTest app covers the cognitive domain using derived items from 6-CIT, a shorter version of BMIC (Blessed Information Memory Concentration Scale), and functional domain using items derived from SCIDS, a shorter version of CIDS (Concord Informant Dementia Scale). The rationale behind choosing these screening methods is as following:

(i) They evaluate cognitive functioning domains

(ii) They are widely evaluated and utilised by healthcare practitioners

(iii) Fulfilment of DSM-V and CDR (Clinical Dementia Rating)

(iv) Ease of use and to administer; 6-CIT and SCIDS take approximately 3-4 minutes and 5-7 minutes respectively

(v) 6-CIT has the best performance in detecting participants with and without dementia amongst the reviewed cognitive screening methods with respect to specificity (100\%) and sensitivity (90\%). (See Table 3 for further details).

(vi) SCIDS has attained a reliable performance for its specificity at $87 \%$ and sensitivity at $83 \%$.

6-CIT is utilized by potential patients (individuals usually aged over 60 years). This assessment method covers the cognitive area and consists of 26 items based on the Blessed Information Memory Concentration Scale (BIMC) as an abbreviated version (Jefferies et al., 2013b). The brevity and simplicity of use for medical practitioners and patients for this test best suits with the integration on a mobile application as it's easy to use and administer and typically completed with an average duration of $5-7 \frac{1}{2}$ minutes. Also, this test can detect dementia in its earliest stages and is easily translatable to other languages; these were the major considerations why we preferred it to the MMSE test. The specificity and sensitivity showed noteworthy rates. 
The second screening method selected was SCIDS and it is used by caregivers of family members who know the participant. This method covers the functional area as it evaluates the domains in the Clinical Dementia Rating (CDR) (Lichtenberg, 2010), namely orientation, memory, judgement, judgement and problem solving, community involvement in home and hobbies, personal care, and language (Waite, 2010). The test derived from the standardised 31-item test devised to evaluate changes on a previous five-year span. The specificity showed superior rates over IQCODE while sensitivity displayed an acceptable ratio. In addition, this screening test manifests no link with education and an even smaller fraction of a relationship with the National Adult Reading Test than MMSE. This method possesses the advantage of everyday operational functioning that offers a measurement of previous deterioration on performance without bias of the educational background of a respondent, and thus confirms its value as a screening test for dementia.

A comparative analysis (Table 3 ) is useful to acquire a general overview of the technical specifications for the short screening tests as it guided us to select which method would be appropriate for this mobile screening application. The aim of Table 3 is to display the existing instruments used to detect early dementia and to specify which cognitive domains are assessed based on an assessment standard such as DSM-IV. Screening methods that assess $\mathrm{MCl}$, also known as the pre-dementia phase, is defined within the context of a decline in cognitive ability but doesn't require help to perform the function include: MMSE, AMTS, 6-CIT, MoCA, and ACE-R. All the questions are tallied for 15 items or below which can be administered in a primary or secondary facility, or by a caregiver, family member, and in self-assessment. The cut-off scores are displayed below with respect to performance, i.e. sensitivity and specificity. 
Table 3: Summary of Existing Screening Methods Using Cognitive Questionnaires (Sheehan, 2012)

\begin{tabular}{|c|c|c|c|c|c|c|c|c|c|}
\hline $\begin{array}{l}\text { Screening } \\
\text { Method }\end{array}$ & Cognitive Domains & $\begin{array}{c}\text { \# of } \\
\text { questions }\end{array}$ & $\begin{array}{l}\text { Time to Use } \\
\text { (min) }\end{array}$ & Gold Standard & Cut-off & Sensitivity & Specificity & Administered & Reference \\
\hline MMSE & $\begin{array}{l}\text { Orientation, attention, } \\
\text { memory, language and } \\
\text { visual-spatial skills, } \\
\mathrm{MCl}\end{array}$ & $15-16$ & $5-10$ & DSM-IV diagnosis & $23 / 24$ & 0.79 & 0.95 & Primary care & $\begin{array}{l}\text { Hancock \& } \\
\text { Larner, } 2011\end{array}$ \\
\hline SMMSE & $\begin{array}{l}\text { Orientation to time } \\
\text { and place, short- and } \\
\text { long-term memory, } \\
\text { registration, recall, } \\
\text { constructional ability, } \\
\text { language and the } \\
\text { ability to understand } \\
\text { and follow commands. }\end{array}$ & 12 & 10 & & 24 & Unknown & Unknown & $\begin{array}{l}\text { Health/aged care } \\
\text { facilities in } A U\end{array}$ & IHPA, 2015 \\
\hline AMTS & $\begin{array}{l}\text { Orientation, } \\
\text { registration, recall and } \\
\text { concentration, } \mathrm{MCl}\end{array}$ & 10 & $3-4$ & $\begin{array}{l}\text { Clinical diagnosis / } \\
\text { MMSE }\end{array}$ & $6 / 7$ on total score & 0.81 & 0.84 & $\begin{array}{l}\text { Primary/ } \\
\text { secondary care } \\
\text { non-specialist } \\
\text { settings }\end{array}$ & $\begin{array}{c}\text { Antonelli } \\
\text { Incalze et al., } \\
2003\end{array}$ \\
\hline 6-CIT & $\begin{array}{l}\text { Memory, calculations, } \\
\text { orientation, } \mathrm{MCl}\end{array}$ & 6 & $3-4$ & $\begin{array}{l}\text { Clinical diagnosis of } \\
\text { dementia /MMSE }\end{array}$ & $7 / 8$ on total score & 0.90 & 1.00 & Primary care & $\begin{array}{c}\text { Brooke \& } \\
\text { Bullock, } 1999\end{array}$ \\
\hline GPCOG & $\begin{array}{l}\text { Time orientation, } \\
\text { visuospatial, } \\
\text { information, recall }\end{array}$ & 11 & 6 & DSM-IV dementia & $10 / 11$ on total score & 0.82 & 0.83 & $\begin{array}{c}\text { General } \\
\text { Practitioner / } \\
\text { Informant }\end{array}$ & $\begin{array}{l}\text { Brodaty et al., } \\
2002\end{array}$ \\
\hline Mini-Cog & $\begin{array}{l}\text { Word registration, } \\
\text { word recall, } \\
\text { visuospatial (clock- } \\
\text { drawing) }\end{array}$ & 3 & 3 & $\begin{array}{l}\text { Independent clinical } \\
\text { diagnosis of } \\
\text { dementia }\end{array}$ & Probably normal/ & 0.76 & 0.89 & Primary Care & $\begin{array}{c}\text { Borson et al., } \\
2003\end{array}$ \\
\hline
\end{tabular}




\begin{tabular}{|c|c|c|c|c|c|c|c|c|c|}
\hline TYM & $\begin{array}{l}\text { Orientation, ability to } \\
\text { copy a sentence, } \\
\text { semantic knowledge, } \\
\text { calculation, verbal } \\
\text { fluency, similarities, } \\
\text { naming, visuospatial, } \\
\text { recall }\end{array}$ & 10 & $5-10$ & DSM-IV dementia & $30 / 31$ & 0.73 & 0.88 & $\begin{array}{c}\text { Can be completed } \\
\text { under supervision } \\
\text { of health } \\
\text { professional }\end{array}$ & $\begin{array}{l}\text { Hancock \& } \\
\text { Larner, } 2011\end{array}$ \\
\hline MoCA & $\begin{array}{l}\text { Orientation, short- } \\
\text { term memory, } \\
\text { executive function, } \\
\text { visuospatial, language, } \\
\text { abstraction, animal } \\
\text { naming, attention, } \\
\text { clock-drawing, } \mathrm{MCl}\end{array}$ & 10 & 10 & $\begin{array}{l}\text { Clinical diagnosis of } \\
\text { Alzheimer's disease }\end{array}$ & $25 / 26$ & 1.00 & 0.87 & $\begin{array}{c}\text { No special } \\
\text { training for health } \\
\text { professionals }\end{array}$ & $\begin{array}{l}\text { Nasreddine, } \\
2005\end{array}$ \\
\hline ACE-R & $\begin{array}{l}\text { Orientation, attention, } \\
\text { memory, verbal } \\
\text { fluency, language, } \\
\text { visuospatial, MCl }\end{array}$ & 26 & $15-20$ & DSM-IV dementia & $73 / 74$ & 0.90 & 0.93 & $\begin{array}{c}\text { Primary } \\
\text { care/secondary } \\
\text { care }\end{array}$ & $\begin{array}{l}\text { Hancock \& } \\
\text { Larner, } 2011\end{array}$ \\
\hline MSQ & $\begin{array}{l}\text { Orientation in time } \\
\text { and place, remote } \\
\text { memory, and general } \\
\text { knowledge }\end{array}$ & 11 & $<5$ & DSM IV, CAM & $5 / 6$ on total score & 0.86 & 0.91 & Primary Care & $\begin{array}{c}\text { Buschke et al., } \\
1999\end{array}$ \\
\hline HDS-R & $\begin{array}{l}\text { Dyscalculia, } \\
\text { orientation } \\
\text { impairments }\end{array}$ & 15 & $5-10$ & $\begin{array}{l}9 \text { dimensions } \\
\text { including assess- } \\
\text { ments for } \\
\text { dyscalculia, } \\
\text { orientation } \\
\text { impairments, and } \\
\text { others }\end{array}$ & $20 / 30$ on total score & 0.90 & 0.82 & $\begin{array}{l}\text { Hospital staff or } \\
\text { family member }\end{array}$ & $\begin{array}{c}\text { Takase et al., } \\
2016\end{array}$ \\
\hline
\end{tabular}




\subsection{DementiaTest Activity}

Figure 2 displays the activity diagram of DementiaTest and a top-level of the essential screens. The activity flow of the application starts from the initial state, wherein the application information can be viewed that contains the description of the application and developer details (see Figure 3a ). In the initial state, the terms and conditions should be agreed upon before proceeding to the next stage that is "Enter Age, Gender, Ethnicity" screen (see Figure 3b). This information must be input and validated accordingly before proceeding. Upon completion and validation of the profile information, the participant will select one of the following options: "Self", "Informant", or "Both" (see Figure 3c). Based on the selection the relevant items related to screening will be retrieved from the database. Each item is displayed on a separate screen and the respondent may click "next" after completion to proceed to the next item. A question related to the "informant" is presented (see Figure 3d) and both of the questions that fall under 6-CIT (see Figures $3 e$ and 3f) are represented by "Self" as a type of test. Once the respondent finishes the screening test, they will have to press the "submit result" button to display the end results (see Figures $3 \mathrm{~g}$ and $3 \mathrm{~h}$ ).

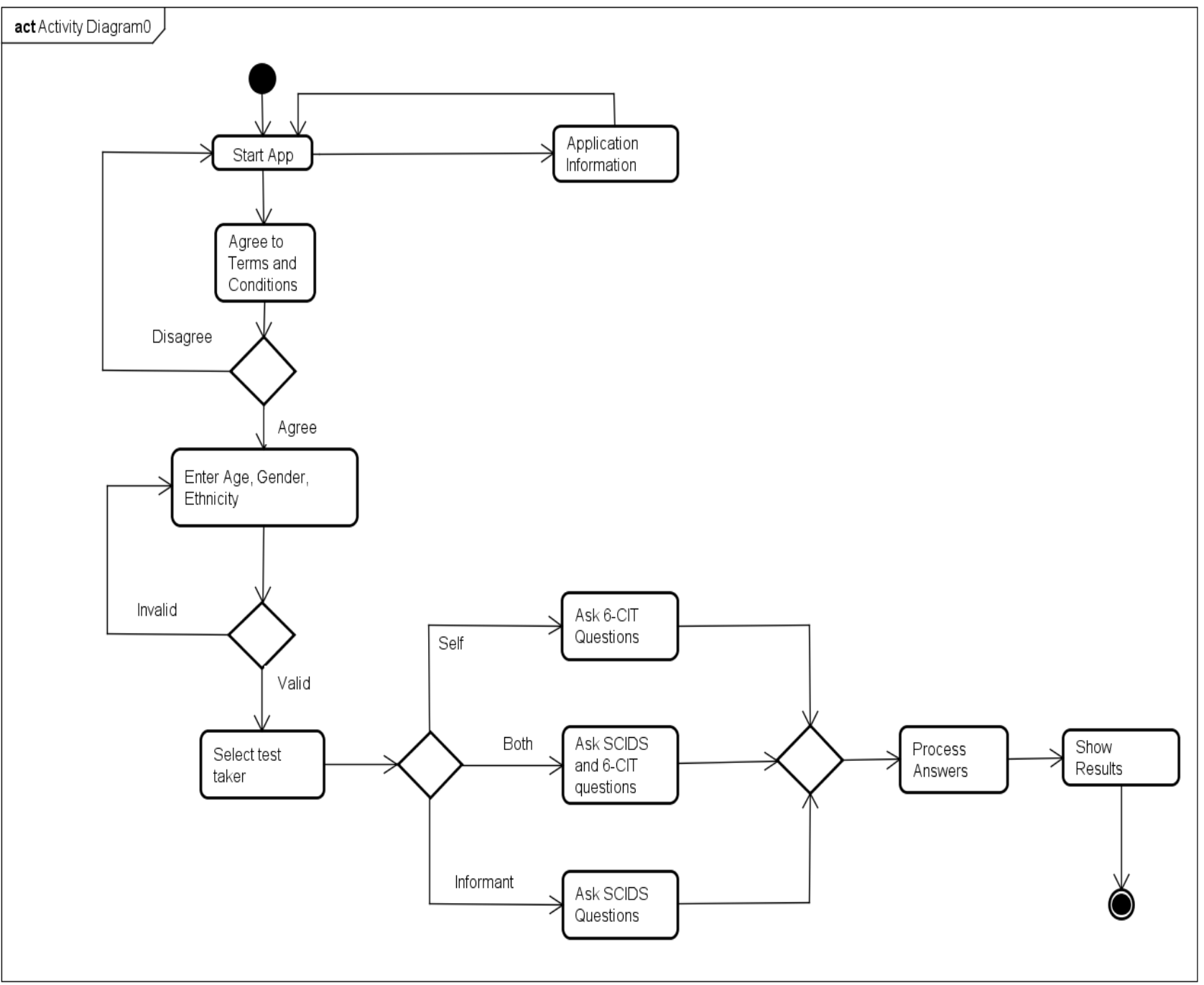

Figure 2: DementiaTest Activity Diagram 


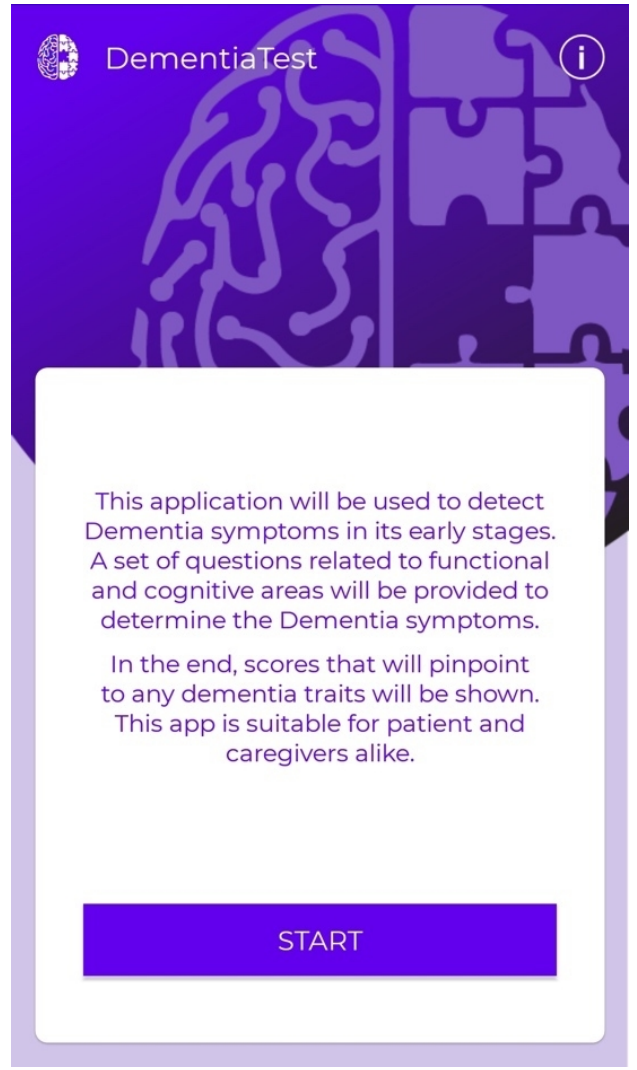

Figure 3a: Information Screen

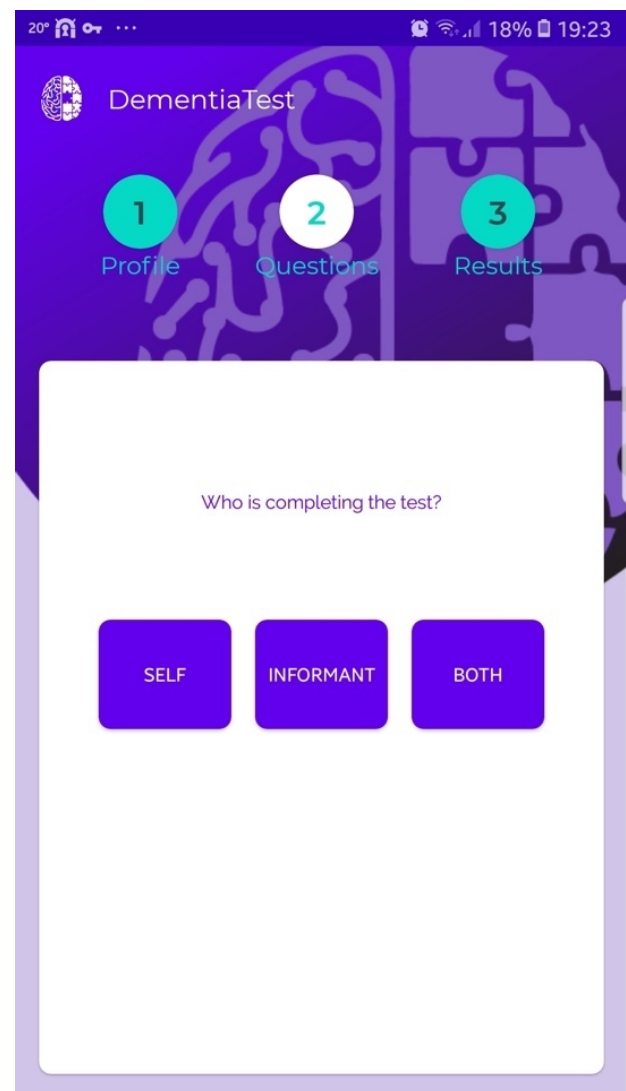

Figure 3c: Type of Test Screening Based on User

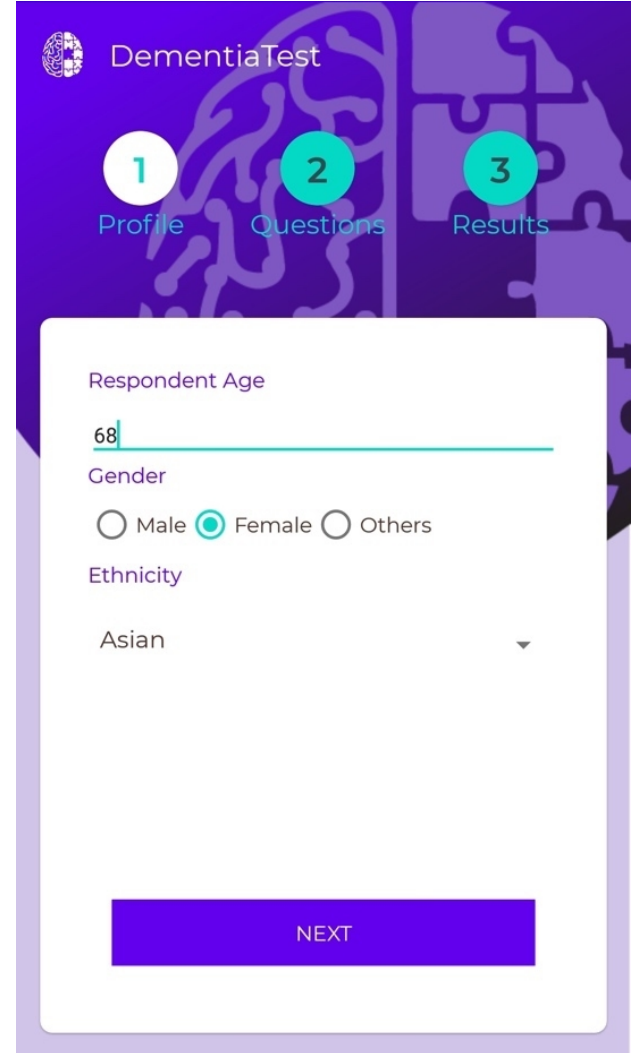

Figure 3b: Data Acquisition Screen

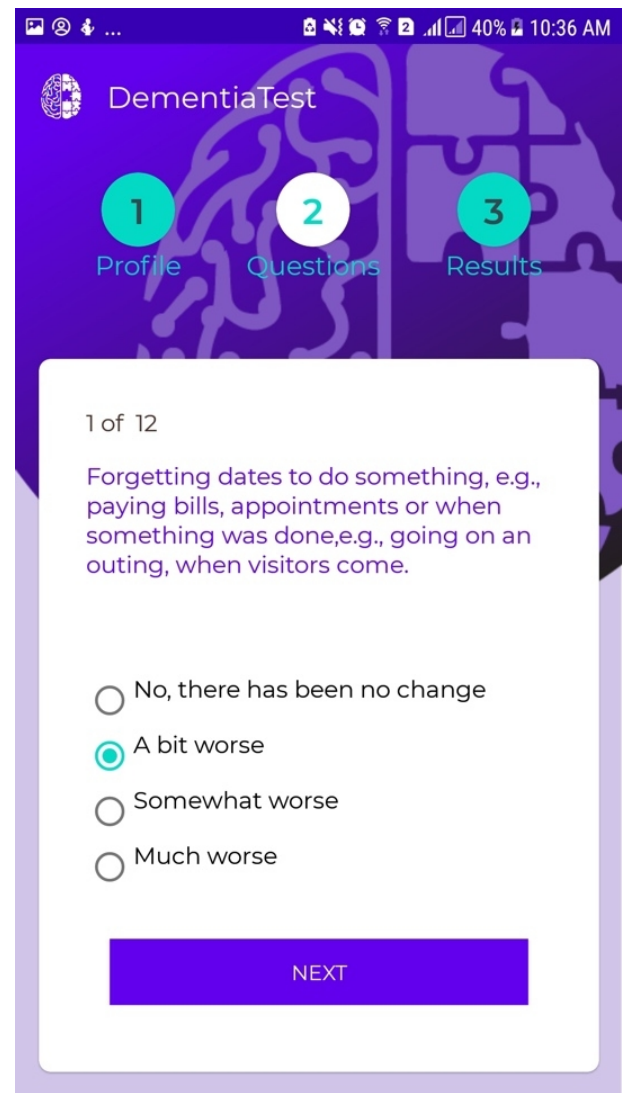

Figure 3d: Sample Question: SCIDS 


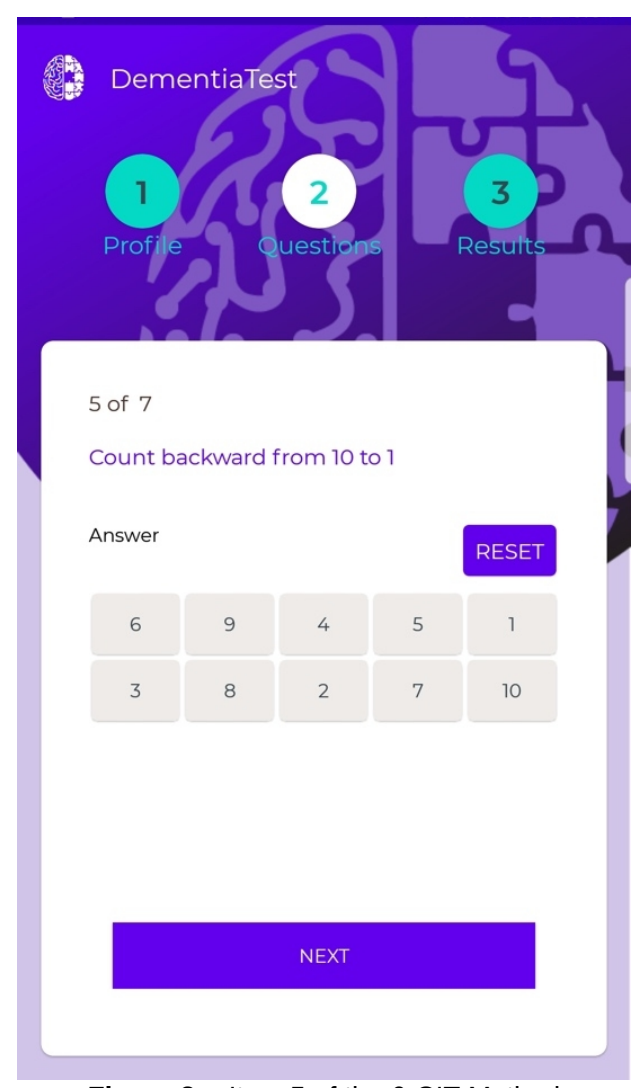

Figure 3e: Item 5 of the 6-CIT Method

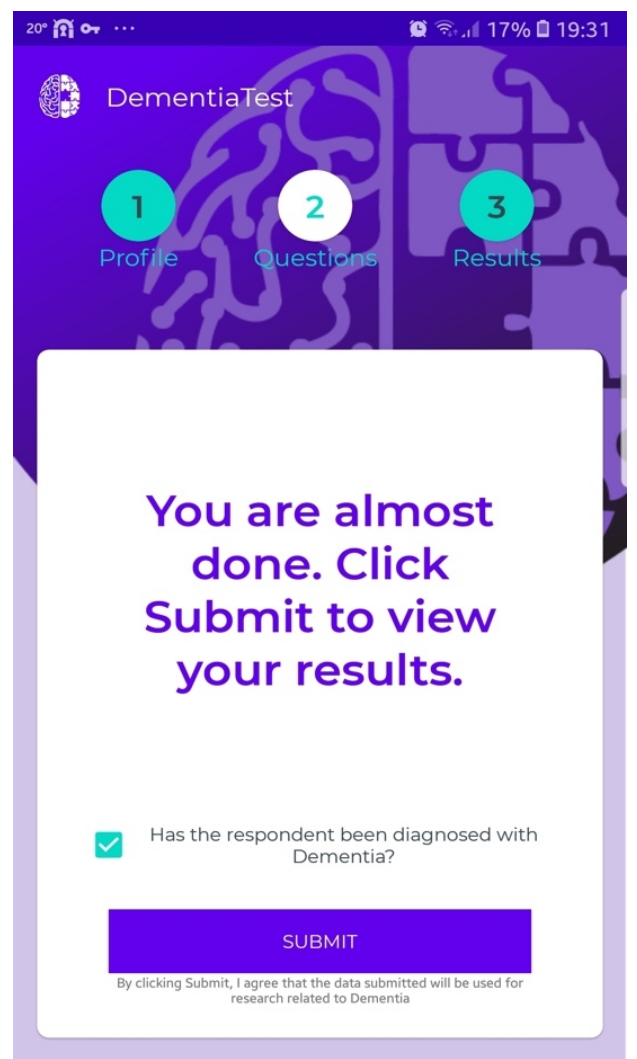

Figure 3g: Submission Page: 6-CIT (Self-Test)

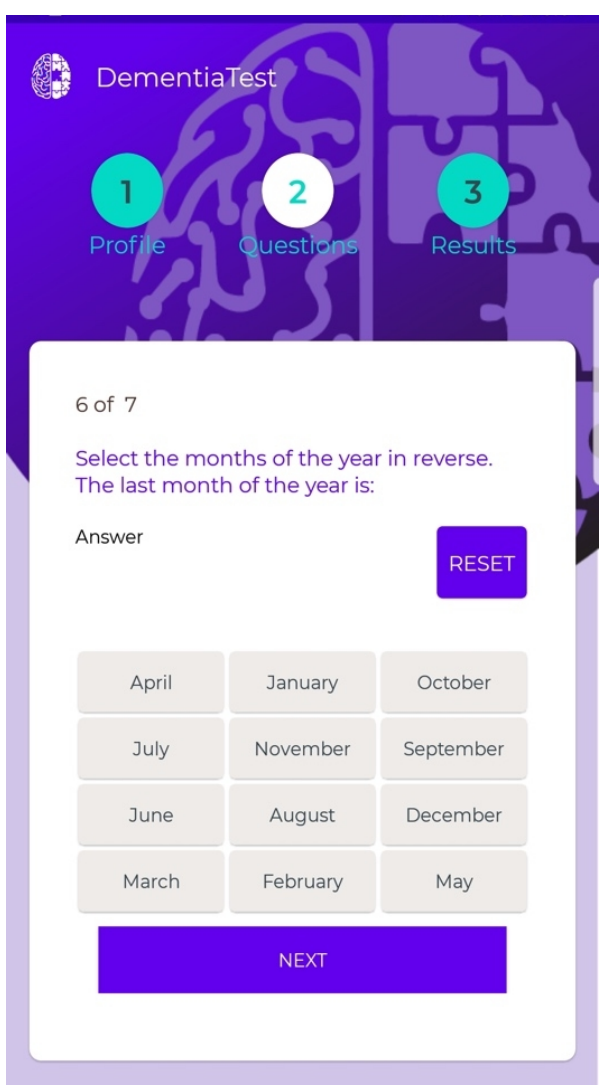

Figure 3f: Item 6 of the 6-CIT Method

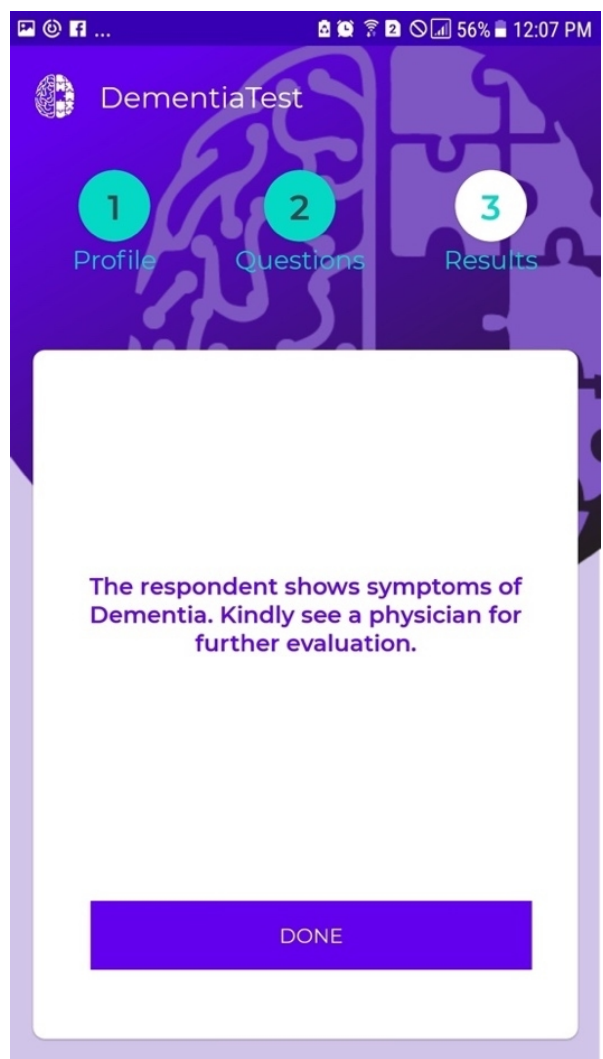

Figure 3h: 6-CIT (Self-Test) Result Screen 


\subsection{Screening Process}

Prior to completing the dementia screening, participants are required to consent to privacy policy, and use of the data. Participants are notified that their answers to the screening questions would be stored anonymous and can be only used for research purposes. No direct contact with participants during the data collection. Since no sensitive information is involved such as name, address, date of birth, etc participant identities are anonymous. More importantly, ethical application submitted to the Manukau Institute of Technology ethics committee was approved for data collection using mobile application in May 2019.

The first screen will serve as the landing screen that provides the application information, terms and conditions, and the agreement to data privacy. A button can be pressed to proceed to the next screen that will display a profile-setting screen. A prompt asking for the user's age, gender, and ethnicity is required. Next, the screening items will be adopted from two screening methods (i) SCIDS and (ii) 6-CIT. The participants taking the test will be prompted for "Self", "Informant", or "Both" and the subsequent items depend on the input provided for this question. Whenever "Self" is selected, 6-CIT questions will be displayed. If "Informant" is selected, then SCIDS questions will be asked. When "Both" is picked, items that belong to 6-CIT and SCIDS will be presented. Upon test completion, a brief results screen will present the attained scores.

The result of the test follows the conventional scoring functions in the 6-CIT and SCIDS screening methods. In particular, if the user initially selected "Self" a score of 4 and above corresponds to dementia traits and a message will advise the user to follow up with his/her physician for a referral for further assessments. If the score is below 4 then a message "no dementia traits are exhibited" will appear. However, if the test selected by the user is "Informant" indicating a caregiver or a family member who is close to the individual is going to undergo the test, then a score of above 10 will indicate that a follow up for further assessments will appear. Whereas if the score is between 0-9 then a message of no dementia traits will be displayed. Finally, if the selected test was "Both" then no score will be displayed although a message based on the items answered will be displayed as follows:

1) If the respondent scored above 4 in SCIDS and above 10 in 6-CIT, the message will display: "The respondent shows symptoms of dementia. Kindly see a physician for further evaluation."

2) If the respondent scored below 4 in SCIDS and between 0-9 in 6-CIT, the message displayed will be: "The respondent does not show any symptoms of dementia."

3) If the results in 6-CIT and SCIDS are conflicting then 6-CIT results will prevail, and the message based on items (1) and (2) will be displayed accordingly.

Table 4: Design of 6-CIT Questions and the Possible Answers

\begin{tabular}{|c|c|c|}
\hline Items & Descriptor & Possible Answers \\
\hline Question 1 & No modifications; 0 = Correct; 1 = No changes & Respondent's answer \\
\hline Question 2 & $\begin{array}{l}\text { Options for particular months are presented in the dropdown menu; } 0=\text { Correct; } 1 \\
=\text { No modifications }\end{array}$ & $\begin{array}{l}\text { Respondent's answer } \\
\text { selected from the } 12 \\
\text { months of the year }\end{array}$ \\
\hline Question 3 & Five static words are displayed to test recall ability & $\begin{array}{l}\text { Default answer is } 0 \\
\text { because question-3 } \\
\text { doesn't require an } \\
\text { answer }\end{array}$ \\
\hline Question 4 & Time is the input value & $\begin{array}{l}\text { Respondent's answer in } \\
\text { 24-hour format }\end{array}$ \\
\hline Question 5 & $\begin{array}{l}\text { The error will be totalled and if it exceeds } 2 \text { the score will be set to } 2 \text {. The } \\
\text { modifications implemented are (a) Instead of counting backwards from } 20 \text { to } 1 \text { it } \\
\text { was replaced by } 10 \text { to } 1 \text { (b) Buttons were utilised instead of text fields, and (c) User } \\
\text { can reset the answer and no error will be reported. }\end{array}$ & Respondent's answer \\
\hline Question 6 & $\begin{array}{l}\text { The modifications are (a) Integrated an } 8 \mathrm{sec} \text {. timer and whenever the time has } \\
\text { lapsed then December would be selected by default therefore the error would be } \\
\text { mapped as } 1 \text { and every occurrence of an error would still be recorded as } 1 \text { entry in } \\
\text { the table, but if it exceeds } 2 \text { the score will be set to } 2 \text { (b). The user can reset the } \\
\text { answer and no error will be reported. }\end{array}$ & Respondent's answer \\
\hline Question 7 & $\begin{array}{l}\text { Every incorrect answer corresponds to two points and when left all as blanks then } \\
10 \text { points will be awarded. Provided answers are not case sensitive. }\end{array}$ & Respondent's answer \\
\hline
\end{tabular}


The material design guidelines will be consistent throughout the implementation of the application. The colour scheme of the application is observed as purple because this is the colour that represents dementia awareness.

\subsection{Database, Privacy and Features Collection}

The questions from 6-CIT were devised to adapt to a mobile framework setting as shown in Table 4 where it outlines the design and logic of each question. More importantly, features CIT-1 to CIT-7 in Table 5 show how each item of the 6-CIT method has been collected during the screening process of dementia. Both the questions and options that appear will not be retrieved from any database, instead they will be derived from the application internally. All the responses from the participant will be stored in a NoSQL format employing Firebase capability.

Features related to early dementia screening are collected using the developed mobile application and stored in a secured cloud server for later analysis. As the DementiaTest app implements two screening methods, data collected can be vital for further analysis to improve the accuracy and efficiency of the screening. During the data collection, there was no direct access to participants; the DementiaTest app provides clear information to the users about their participation and the use of their data in a disclaimer. In addition, it clearly states the use of the data is only for research purposes and informs the users about the use of their data. The participants read this before submitting their answers. Anonymity has been imposed in the mobile app used to collect the data. Participants' identity is anonymous since no names or sensitive information are involved (see variables in Table 5).

Table 5 shows the key variables collected plus the type of screening, i.e. class label. The class label was assigned in an automatic manner during the process of screening based on the method's final score obtained by the individual after taking the screening. There are two possible values of the class in case the set questions fall under SCIDS method i.e. "yes" which corresponds that the individual has dementia symptoms, or "no" if there is no indication that the individual has dementia symptoms (see Tables 5 and 6 for the items and the possible scoring within the DementiaTest app). In the case of the 6-CIT method, the "yes" label is assigned when the final score based on the 6-CIT scoring function is more than 10 otherwise "maybe" is assigned for scores between 5 and 9 and "no" was assigned for scores between 0 and 4. However, if the screening method used was "both" then the class label value of "No" is obtained and if the final score generated is below 10 in 6-CIT, otherwise "Yes" was assigned to the class label. If the results in 6-CIT and SCIDS are both "Yes" then the final

Table 5: Features Collected, their Descriptions and Mapping to the Actual 6-CIT Questionnaire

\begin{tabular}{|l|l|l|}
\hline Variable & Type & Description \\
\hline Age & Number & Older than 60 \\
\hline Gender & String & Male, Female, Others \\
\hline Ethnicity & String & List of ethnicities \\
\hline Date taken & DateTime & Current date and time for answer tracking \\
\hline CIT-1 & Integer & Correct: 0; Incorrect: 1 \\
\hline CIT-2 & String & Correct: 0; Incorrect: 1 \\
\hline CIT-3 & String & John, Smith, 42, High Street, Bedford \\
\hline CIT-4 & String & Answer is +1 hour: 0; More than \pm 1 -time difference: 3 \\
\hline CIT-5 & String & No wrong answer: 0; 1 wrong answer: 1; More than 2 wrong answers: 2 \\
\hline CIT-6 & String & $\begin{array}{l}\text { No wrong answer: 0; 8 seconds timer is up incurring 1, every wrong } \\
\text { answer is 1; once score reaches 2, score will be fixed to 2 }\end{array}$ \\
\hline CIT-7 & No wrong answer: 0; Each wrong answer incurs 2; All blanks: 10 \\
\hline isDiagnosed & String & $\begin{array}{l}\text { True or false (whether the participant has been formally diagnosed with } \\
\text { dementia) }\end{array}$ \\
\hline Total score & Boolean & Summation of all sub-scores of (CIT-1 to CIT-7) \\
\hline Class & The decision of the screening based on the scoring score of 6-CIT \\
& Integer & method. Possible values are "no" (0-4), "maybe" (5-9), and "yes" (10+). \\
\hline
\end{tabular}


class label is "Yes". If the results in 6-CIT and SCIDS are both "No" then the final class label is "No". However, if the results in 6-CIT and SCIDS are conflicting, the 6-CIT's class will be taken.

Table 6 shows the 12-items included within the SCIDS screening method in which the caregiver should answer on the behalf of the participants in the DementiaTest app. More importantly, the app collects useful features related to the participants when a caregiver is undergoing the test on their behalf as depicted in Table 7. SCIDS-1 to SCIDS-12 features are stored based on the given answers and they correspond to answers associated with item-1 to item-12 in the conventional SCIDS method. The total score feature is computed based on the values assigned to SCIDS- 1 to SCIDS-12 features using the answers given by the participants while conducting the screening. Then using the total score variable, another variable was created to assign the right class value. To be exact, if the value in the final score variable is between $0-4$, the class value assigned will be "No". If the totalscore value is larger than 4 then the value assigned to the class variable will be "Yes". The process of computing the total score and assigning class values is automated within the DementiaTest app.

Table 6: Design of SCIDS Questionnaire and the Possible Answers

\begin{tabular}{|c|c|c|}
\hline Question-1 & $\begin{array}{l}\text { Forgetting dates to do something, e.g., paying bills, } \\
\text { appointments or when something was done, e.g., going on an } \\
\text { outing, when visitors come. }\end{array}$ & $\begin{array}{l}\text { No, there has been no change; A bit worse; Somewhat worse; } \\
\text { Much worse }\end{array}$ \\
\hline 2 & Forgetting where he/she put something. & $\begin{array}{l}\text { No, there has been no change; A bit worse; Somewhat worse; } \\
\text { Much worse }\end{array}$ \\
\hline 3 & Forgetting what someone just told him/her. & $\begin{array}{l}\text { No, there has been no change; A bit worse; Somewhat worse; } \\
\text { Much worse }\end{array}$ \\
\hline 4 & Forgetting his/her address or telephone number. & $\begin{array}{l}\text { No, there has been no change; A bit worse; Somewhat worse; } \\
\text { Much worse }\end{array}$ \\
\hline 5 & Forgetting where things are usually kept. & $\begin{array}{l}\text { No, there has been no change; A bit worse; Somewhat worse; } \\
\text { Much worse }\end{array}$ \\
\hline 6 & $\begin{array}{l}\text { Not knowing where to find things that have been put in a } \\
\text { different place than usual. }\end{array}$ & $\begin{array}{l}\text { No, there has been no change; A bit worse; Somewhat worse; } \\
\text { Much worse }\end{array}$ \\
\hline 7 & $\begin{array}{l}\text { Forgetting things about family and friends, e.g., where friends } \\
\text { live, social occasions that may have happened in the past. }\end{array}$ & $\begin{array}{l}\text { No, there has been no change; A bit worse; Somewhat worse; } \\
\text { Much worse }\end{array}$ \\
\hline 8 & $\begin{array}{l}\text { Not recognizing the faces of people, he/she knows, e.g., friends, } \\
\text { neighbours. }\end{array}$ & $\begin{array}{l}\text { No, there has been no change; A bit worse; Somewhat worse; } \\
\text { Much worse }\end{array}$ \\
\hline 9 & Forgetting what day, month and year it is. & $\begin{array}{l}\text { No, there has been no change; A bit worse; Somewhat worse; } \\
\text { Much worse }\end{array}$ \\
\hline 10 & $\begin{array}{l}\text { Forgetting whether it was breakfast or dinner at the appropriate } \\
\text { times. }\end{array}$ & $\begin{array}{l}\text { No, there has been no change; A bit worse; Somewhat worse; } \\
\text { Much worse }\end{array}$ \\
\hline 11 & $\begin{array}{l}\text { Losing his/her way around places that are familiar to him/her, } \\
\text { e.g., the local shops, when driving in places that are familiar to } \\
\text { him/her (visiting family and friends), or in the home (finding } \\
\text { where the bathroom is). }\end{array}$ & $\begin{array}{l}\text { No, there has been no change; A bit worse; Somewhat worse; } \\
\text { Much worse }\end{array}$ \\
\hline 12 & $\begin{array}{l}\text { Losing his/her way around places outside his/her usual } \\
\text { neighbourhood, e.g., the city }\end{array}$ & $\begin{array}{l}\text { No, there has been no change; A bit worse; Somewhat worse; } \\
\text { Much worse }\end{array}$ \\
\hline
\end{tabular}

\section{Conclusions and Implications}

Most of the existing screening applications to detect early dementia traits are not focused on the entire cognitive functioning capacity; this leads to partial assessment and not fulfilling the neurocognitive disorders criteria of DMS-V. Conventional screening methods are often conducted manually in medical clinics which requires the participant to visit a specialised healthcare centre and the presence of diagnosticians. In addition, the majority of existing screening methods to detect dementia utilize long questionnaires and are not accessible to patients and their family members. There are a few existing mobile applications that deal with pre-diagnosis of dementia such as $\mathrm{MCl}$ and others; these methods mainly cover some cognitive functioning areas, so they can be criticised for not being comprehensive. 
There is an opportunity to fill the gaps by developing a novel screening mobile application for the early detection of dementia, hence the DementiaTest. This screening app is comprehensive as it measures cognitive and functional domains of assessments thus fulfilling the DSM-V standard. The proposed screening app integrates SCIDS and 6-CIT methods to screen cognitive functioning domains of individuals including learning, problem solving, remembering, attention, decision making and reasoning among others. The simplicity of the design and the use of purple colouring which aligns with "dementia awareness", make the DementiaTest screening app attractive. More importantly, the dementia app establishes a data repository for collecting vital features related to dementia including 23 variables related to cognitive functioning; further analyses of observations can help improve the accuracy and efficiency of the screening. The DementiaTest app is crucial for screening of dementia as it increases stakeholder's accessibility including patients at an early stage, care givers, family members, medical staff, and clinicians among others. This app is available in both Android and IOS operating systems and it provides time-efficient pre-diagnosis without the need to be present in a medical clinic with specialised clinicians. Thus, we expect that busy medical clinics to highly benefit from his app, especially to speed up further assessments for formal diagnosis of individuals potentially having dementia.

This mobile application is advantageous for family members, patients, and the healthcare system to acquire for their smart mobile devices or medical software system as they need a reliable screening method to identify the symptoms of early dementia. This mHealth app would be beneficial for the medical healthcare system as it would supplement their patient care process. DementiaTest also promotes an easy-to-use measure for future clinical visits for a more meticulous clinical diagnosis.

In the near future, we intend to investigate replacing the scoring of the conventional medical screening to improve the accuracy of DementiaTest using Artificial Intelligence and machine learning. The static scoring function within conventional medical screening of dementia would be replaced by an intelligent scoring system derived from deep learning using Artificial Neural Networks (ANN) to improve the screening's sensitivity and specificity in discriminating participants with and

Table 7: Features Collected, their Descriptions and Mapping to the Actual SCIDS Questionnaire

\begin{tabular}{|c|c|c|}
\hline Variable & Type & Description \\
\hline Age & Number & Older than 60 \\
\hline Gender & String & Male, Female, Others \\
\hline Ethnicity & String & List of ethnicities \\
\hline SCIDS-1 & Integer & $\begin{array}{l}\text { No, there has been no change: } 0 \text {; A bit worse: } 1 \text {; Somewhat worse: } 2 \text {; } \\
\text { Much worse: } 3\end{array}$ \\
\hline SCIDS -2 & Integer & $\begin{array}{l}\text { No, there has been no change: } 0 \text {; A bit worse: } 1 \text {; Somewhat worse: } 2 \text {; } \\
\text { Much worse: } 3\end{array}$ \\
\hline SCIDS -3 & Integer & $\begin{array}{l}\text { No, there has been no change: } 0 \text {; A bit worse: } 1 \text {; Somewhat worse: } 2 \text {; } \\
\text { Much worse: } 3\end{array}$ \\
\hline SCIDS -4 & Integer & $\begin{array}{l}\text { No, there has been no change: } 0 \text {; A bit worse: } 1 \text {; Somewhat worse: } 2 \text {; } \\
\text { Much worse: } 3\end{array}$ \\
\hline SCIDS -5 & Integer & $\begin{array}{l}\text { No, there has been no change: } 0 \text {; A bit worse: 1; Somewhat worse: } 2 \text {; } \\
\text { Much worse: } 3\end{array}$ \\
\hline SCIDS -6 & Integer & $\begin{array}{l}\text { No, there has been no change: 0; A bit worse: 1; Somewhat worse: } 2 \text {; } \\
\text { Much worse: } 3\end{array}$ \\
\hline SCIDS -7 & Integer & $\begin{array}{l}\text { No, there has been no change: 0; A bit worse: 1; Somewhat worse: } 2 \text {; } \\
\text { Much worse: } 3\end{array}$ \\
\hline SCIDS -8 & Integer & $\begin{array}{l}\text { No, there has been no change: 0; A bit worse: 1; Somewhat worse: 2; } \\
\text { Much worse: } 3\end{array}$ \\
\hline SCIDS -9 & Integer & $\begin{array}{l}\text { No, there has been no change: } 0 \text {; A bit worse: } 1 \text {; Somewhat worse: } 2 \text {; } \\
\text { Much worse: } 3\end{array}$ \\
\hline SCIDS -10 & Integer & $\begin{array}{l}\text { No, there has been no change: } 0 \text {; A bit worse: } 1 \text {; Somewhat worse: } 2 \text {; } \\
\text { Much worse: } 3\end{array}$ \\
\hline SCIDS -11 & Integer & $\begin{array}{l}\text { No, there has been no change: } 0 \text {; A bit worse: } 1 \text {; Somewhat worse: } 2 \text {; } \\
\text { Much worse: } 3\end{array}$ \\
\hline SCIDS -12 & Integer & $\begin{array}{l}\text { No, there has been no change: 0; A bit worse: 1; Somewhat worse: 2; } \\
\text { Much worse: } 3\end{array}$ \\
\hline isDiagnosed & Boolean & $\begin{array}{l}\text { True or false (whether the participant has been formally diagnosed with } \\
\text { dementia) }\end{array}$ \\
\hline Total Score & Integer & Summation of SCIDS-1 to SCIDS-12 items \\
\hline Class & String & $\begin{array}{l}\text { The decision of the screening based on the scoring score of SCIDS } \\
\text { method. Possible values are "no" }(0-4) \text {, or "yes" (4+). }\end{array}$ \\
\hline
\end{tabular}


without dementia. One of the possible limitations of this study is not having enough data observations in order to show the impact of machine learning and intelligent methods. However, in near future and when we have enough numbers of observations, we will show whether machine learning methods are able to improve screening performance of dementia using cognitive functioning features. Machine learning and computational intelligence techniques such as rule induction, decision trees and deep learning can identify concise influential set of dementia features and reveal useful correlations between features and the response variable. More importantly, these techniques can be utilized to design new screening methods based on learning models derived from cases and controls, which will be more efficient and advantageous for diagnosticians and other medical professionals interested in dementia diagnosis and screening.

\section{Compliance with Ethical Standards}

Funding: This study has not been funded by particular entity

Conflict of Interest: All authors declare no conflict of interest

Ethical approval: This article does not contain any studies with human participants performed by any of the authors. 


\section{References}

1. Analysis, D. (2018) Dementia \& Alzheimer's Memory Diagnosis Test: MMSE [Mobile Application]. Available from: https://play.google.com/store/apps/details? id=com.alzheimers mme

2. APA. (2013) DSM-V (5 $5^{\text {th }}$ ed.). Washington, DC, USA.

3. Berauk, V. L. A. (2017) Mobile Health Applications for Caring of Older People: Review and Comparison. Sagepub. https://doi.org/DOI: 10.1177/2168479017725556

4. Borson, S., Scanlan, J., Chen, P., \& Ganguli, M. (2003) The Mini-Cog as a Screen for Dementia: Validation in a Population-Based Sample (Vol. 51). https://doi.org/10.1046/j.15325415.2003.51465.x

5. Brooke, P., \& Bullock, R. (1999) Validation of a 6 Item Cognitive Impairment Test with a view to Primary Care Usage. Wiley \& Sons Ltd.

6. Chaturvedi, K. (2018) Cognitive Questionnaire Test [Mobile Application]. Available from https://play.google.com/store/apps/details?id=com.questionnaire.questionnaire

7. Chewy Logic, LLC. (2018) eSLUMS [Mobile Application]. Available from: https://itunes.apple.com/us/app/eslums/id1141690870

8. Cunningham, E. L., McGuinness, B., Herron, B., \& Passmore, A. P. (2015) Dementia. The Ulster Medical Journal, 84(2), 79-87. Available from: https://www.ncbi.nlm.nih.gov/pubmed/26170481

9. Cyber, P. H. (2018) Dementia Test - risk calculator of dementia [Mobile Application]. Available from: https://itunes.apple.com/us/app/dementia-test-risk-calculator-of-dementia/ id $1014958634 ? \mathrm{mt}=8$

10. Deloitte. (2017) Dementia Economic Impact Report 2016. Available from: http://www.alzheimers.org.nz/getmedia/79f7fd09-93fe-43b0-a837-771027bb23c0/ Economic-Impacts-of-Dementia-2017.pdf/

11. Dementia Risk Tool - Apps on Google Play. (2018) Available from: https://play.google.com/store/apps/details?id=com.dementiarisktool\&hl=en US

12. Fan, Y.-C., Hsu, J.-L., Tung, H.-Y., Chou, C.-C., \& Bai, C.-H. (2017) Increased dementia risk predominantly in diabetes mellitus rather than in hypertension or hyperlipidaemia: $\mathrm{A}$ population-based cohort study. Alzheimer's Research \& Therapy, 9(1), 7-7. https://doi.org/10.1186/s13195-017-0236-z

13. Google Developers. (2018) Firebase. Available from: https://firebase.google.com/ (Accessed 17 November 2018).

14. Gorelick, P. B., Scuteri, A., Black, S. E., Decarli, C., Greenberg, S. M., ... Ladecola, C., (2011) Vascular contributions to cognitive impairment and dementia: A statement for healthcare professionals from the American heart association/American stroke association. Stroke, 42(9), 2672-2713. https://doi.org/10.1161/STR.0b013e3182299496

15. Harrison, J. K., Noel-Storr, A. H., Demeyere, N., Reynish, E. L., \& Quinn, T. J. (2016) Outcomes measures in a decade of dementia and mild cognitive impairment trials. Alzheimer's Research \& Therapy, 8(1), 48-48. https://doi.org/10.1186/s13195-016-0216-8

16. IHPA. (2015) Standardised Mini-Mental State Examination (SMMSE) [Text]. Available from: https://www.ihpa.gov.au/what-we-do/standardised-mini-mental-state-examination-smmse. (Accessed 10 October 2018)

17. Jefferies, K., \& Gale, T. M. (2013a) Montreal Cognitive Assessment. In A. J. Larner (ed.), Cognitive Screening Instruments: A Practical Approach. London: Springer London. https://doi.org/10.1007/978-1-4471-2452-8 11

18. Jefferies, K., \& Gale, T. M. (2013b) Sensitive Online Cognitive Assessment. In A. J. Larner (ed.), Cognitive Screening Instruments: A Practical Approach. London: Springer London. https://doi.org/10.1007/978-1-4471-2452-8 11 
19. Jefferies, K., \& Gale, T. M. (2013c) 6-CIT: Six-Item Cognitive Impairment Test. In A. J. Larner (Ed.), Cognitive Screening Instruments: A Practical Approach (pp. 209-218). London: Springer London. https://doi.org/10.1007/978-1-4471-2452-8 11

20. Jorm, A. F., Scott, R., Cullen, J. S., \& MacKinnon, A. J. (1991) Performance of the Informant Questionnaire on Cognitive Decline in the Elderly (IQCODE) as a screening test for dementia. Psychological Medicine, 21(3), 785-790.

21. Langa, K. M., \& Levine, D. A. (2014) The diagnosis and management of mild cognitive impairment: A clinical review. JAMA, 312(23), 2551-2561.

https://doi.org/10.1001/jama.2014.13806

22. Lichtenberg, P. A. (2010) Handbook of Assessment in Clinical Gerontology (2nd ed.).

23. Mind Diagnostics, I. (2018) Mental Health Test [Mobile Application]. Available from: https:// play.google.com/store/apps/details?id=org.minddiagnostics

24. Nasreddine, Z., Philips, N., Bédirian, V., \& Chertkow, H. (2005) MoCA. ResearchGate, 695699. https://doi.org/DOI: 10.1111/j.1532-5415.2005.53221.x

25. New York University. (2015) ConsultGeri: Dementia [Mobile Application]. Retrieved from https://play.google.com/store/apps/details?id=appinventor.ai openmylabfeed.MMSEDemo

26. NYU. (2015) Dementia | ConsultGeri Topic. Available from: https://consultgeri.org/geriatrictopics/dementia. (Accessed 16 November 2018).

27. Openmylab. (2018) Folstein Test [Mobile Application]. Available from: https://play.google.com/store/apps/details?id=appinventor.ai openmylabfeed.MMSEDemo

28. Panegyres, P. K., Berry, R., \& Burchell, J. (2016) Early Dementia Screening. Diagnostics, 6(1). https://doi.org/10.3390/diagnostics6010006

29. Proctor Corporation Ltd. (2018) Confusion: Delirium \& Dementia (Version 1.2). Available from: https://itunes.apple.com/gb/app/confusion-delirium-dementia/id680177778? mt=8

30. Tanriverdi, Y. (2018) MMSE [Mobile Application]. Available from https://play.google.com/store/apps/details?id=com.yasintanriverdi.mmse

31. Waite, L. M. (2010) Aging, Neuropsychology, and Cognition: A Journal on Normal and Dysfunctional Development. http://dx.doi.org/10.1076/anec.5.3.194.614

32. Wascher, T. (2018) SoCA Dementia Test [Mobile Application]. Available from: https://play.google.com/store/apps/details? id=appinventor.ai TOMMYBONN2011.soca english

33. WHO. (2011) mHealth (Vol. 3). Geneva: World Health Organization.

34. WHO. (2017) Dementia. Available from: http://www.who.int/news-room/fact-sheets/detail/ dementia. (Accessed 28 October 2018)

35. Zorluoglua, G. (2014) A mobile application for cognitive screening of dementia. Elsevier Ireland Ltd. http://dx.doi.org/10.1016/j.cmpb.2014.11.004

36. Hancock P., \& Larner A. (2011).Test Your Memory test: Diagnostic utility in a memory clinic population. Int J Geriatr Psychiatry 25: 976-980.

37. Buschke, H., Kuslansky, G., Katz, M., Stewart, W. F., Sliwinski, M. J., ... Eckholdt, H. M. (1999) Screening for dementia with the Memory impairment Screen. Neurology 52: 231-238

38. Brodaty H., Pond D., Kemp N., Luscombe G., Harding L., Berman K., et al. (2002) The GPCOG: a new screening test for dementia designed for general practice. J Am Geriatric Society 50 : 530-534

39. Antonelli Incalze, R., Cesare, M., Pedone, C., Carosella, L., \& Carbonin, P. U. (2003) Construct validity of the abbreviated mental test in older medical inpatients. Dement Geriatr Cogn Disord 15: 199-206

40. Takase, Y., Sakakibara, M., \& Igarashi, A. (2016) Simplified Questionnaire for Early Detection of Dementia. Japan Primary Care Association, 17, 83-89.

41. Sheehan, B. (2012). Assessment scales in dementia. Therapeutic Advances in Neurological Disorders, 5(6), 349-358. https://doi.org/10.1177/1756285612455733 
